\title{
LIBERALISMO, REPRESENTATIVIDAD, DERECHO AL VOTO Y ELECCIONES EN LA PRIMERA MITAD DEL SIGLO XIX EN MÉXICO
}

Reynaldo Sordo*

\section{El liberalismo político fue un gran} movimiento intelectual que cambió al mundo occidental en los siglos XVII, XVIII y XIX. Como afirma André Jardin, este movimiento hubiera sido sólo un 'fantasma sin carne' si no hubiera conquistado a grupos sociales que se esforzaron por llevar sus convicciones a las instituciones y a las leyes. ${ }^{1}$ El liberalismo político fue ante todo, un movimiento en contra del absolutismo, y por esta razón, donde se manifestó con mayor claridad fue en los momentos de crisis de la cuádruple revolución: la inglesa del siglo XVII, la norteamericana y francesa del siglo XVIII y la hispana de principios del XIX.

A lo largo de estos siglos, las naciones construyeron una nueva concepción del Estado, de las instituciones y prácticas políticas, muchas de ellas vigentes hasta nuestros días. A grandes rasgos, la nueva concepción liberal del hombre y su relación con el poder político

* Departamento Académico de Estudios Generales, ITAM.

${ }^{1}$ André Jardín, Historia del liberalismo politico. De la crisis del absolutismo a la Constitución de 1875, 1985, México, FCE, p. 7. 
tendría como principios cardinales: el reconocimiento de la existencia de unos derechos naturales imprescriptibles del hombre, la igualdad jurídica de los seres humanos, la ley como la expresión de la voluntad general, la idea de que todo poder procede del consentimiento de los gobernados directamente o a través de sus representantes, la necesidad de una constitución escrita, una ley fundamental por encima de los poderes públicos, la división de los mismos y la rendición de cuentas de todo agente público sobre su administración.

En gran medida, la mayoría de estos principios quedaron expresados en la Declaración de los Derechos del Hombre y del Ciudadano, aprobados por la Asamblea Nacional de Francia, el 26 de agosto de 1789, pasando a formar parte de la primera constitución revolucionaria del 3 de septiembre de 1791. ${ }^{2}$ Ernst Cassirer escribe sobre la importancia de esta Declaración: "La filosofía francesa del XVIII no ha inventado la idea de los derechos inalienables; pero es la primera que la ha convertido en un verdadero evangelio moral, defendiéndola y propagándola con entusiasmo. Mediante esta su propaganda apasionada la ha introducido en la vida política real, la ha dotado de la fuerza de choque y de explosión que reveló en los días de la Revolución."

Para el tema que nos ocupa, el artículo $6^{\circ}$ de la Declaración decía a la letra: "La ley es la expresión de la voluntad general. Todos los ciudadanos tienen el derecho de participar personalmente o por medio de sus representantes en su formación. Debe ser la misma para todos, tanto si protege como si castiga. Todos los ciudadanos, al ser iguales ante ella, son igualmente admisibles a todas las dignidades, puestos y empleos públicos, según su capacidad y sin otra distinción que la de sus virtudes y la de sus talentos." "Este artículo nos lleva a tres problemas importantes: el carácter de la representación, los derechos políticos de

${ }^{2}$ G. Jellinek, E. Boutmy, E. Doumergue y A. Posada, Orígenes de la Declaración de Derechos del Hombre y del Ciudadano, 1984, Madrid, Editora Nacional, p. 267-70.

${ }^{3}$ Ernst Cassirer, Filosofía de la Ilustración, 1975, México, FCE, p. 278.

4 "Declaración de los Derechos del Hombre y del Ciudadano", en Jellinek, op. cit., p. $267-70$. 
los ciudadanos y el nuevo sentido de las elecciones, indispensables para formar el sistema representativo.

Con respecto a la representación, una primera consideración sería la de que ésta se puede entender en sentido amplio o restringido. La Declaración de 1789 la considera en sentido amplio; de esta forma las autoridades ejecutivas y judiciales serían representativas. Sin embargo, el liberalismo construyó la teoría de la representación en un sentido restringido. "La representación parece así estrechamente vinculada a la elección: los miembros del Legislativo son representantes porque son elegidos por la nación." 5

Una segunda consideración se refiere a cómo el liberalismo político concebía la representación. Es indudable que en la Edad Media y en la era del absolutismo existió la representación. Ésta era una traducción de la separación entre rey y reino y el consenso de éste último al recto gobierno del primero. La representación medieval cristalizó en los Estados Generales, Parlamentos y Cortes, que incluían a los diferentes núcleos territoriales e institucionales del poder: reinos, ciudades, comunidades religiosas, organismos judiciales. La representación se parecía más a la del derecho privado, las elecciones se hacían por aclamación y eran designadas las personas con posiciones de preeminencia. Las Cortes y Parlamentos eran convocados por los reyes, sobre todo para la recaudación de impuestos. Con las crecientes necesidades económicas de los monarcas, en estos organismos de representación se negociaban las concesiones tributarias a cambio de la obtención de ciertos beneficios para determinada corporación. En consecuencia, el representante era un apoderado que sólo podía actuar en los términos del poder otorgado por su corporación. ${ }^{6}$ Con el estado absolutista, el sistema de representación política entraría en decadencia, desde que la tributación se hizo permanente y el rey no tenía ya que acudir a los Estados para conseguir recursos.

${ }^{5}$ Antonio de Cabo de la Vega, El derecho electoral en el marco teórico y jurídico de la representación, 1994, México, UNAM-Instituto de Investigaciones Legislativas, p. 59. En este sentido va a ser considerada en esta exposición.

${ }^{6}$ Idem, p. 35-9. 
En el mundo anglosajón fue donde primeramente la teoría de la representación medieval se vio alterada. Inglaterra sufrió una revolución política en el siglo XVII. La revolución puritana produjo en 1653 la primera constitución escrita de los tiempos modernos: el llamado Instrumento de Gobierno y la revolución gloriosa de 1688, el Bill of Rights. En ellos se delineaban ideas importantes que iban a modificar el concepto de representación medieval, como la idea de la supremacía del Parlamento. ${ }^{7}$

La revolución americana permitió poner en práctica las ideas liberales sobre la representación en las constituciones elaboradas por los estados y en la Constitución federal. La participación estaría basada en la igualdad de los individuos. Los americanos, libres de las corporaciones medievales o estamentales, estarían preparados para poner en práctica la idea del liberalismo político: un ciudadano, un voto. En los Estados Unidos el debate estaría centrado sobre quiénes deberían de votar.

En la Francia revolucionaria es donde con mayor fuerza la nueva teoría liberal entraría en conflicto con el Antiguo Régimen. Por otro lado, el mundo hispánico se vería influido, sobre todo, por el ejemplo francés. Gueniffey explica con claridad el nuevo concepto de representación liberal: "En 1789, la Constituyente había roto con la doctrina tradicional de la representación, que convertía a los diputados en mandatarios sin autonomía, y a su asamblea en una copia fiel de la pluralidad de los intereses realmente existentes. Los revolucionarios consideraron a la nación como una reunión de individuos iguales y a la representación como un órgano deliberante encargado de pronunciar la voluntad común. Por consiguiente, el elemento de la representación ya no constituía un conjunto de cuerpos separados, sino la calidad común de la ciudadanía. Por ello, la representación no apuntaba a obtener un compromiso entre intereses opuestos sino a definir el interés general por una deliberación común."

${ }^{7}$ s/a, An Introduction to Contemporary Civilization in the West, 1946, New York, D. R. Columbia University Press, cap. X, p. 1-15.

${ }^{8}$ Patrice Gueniffey, La Revolución francesa y las elecciones. Democracia y representación a fines del siglo XVIII, 2001, México, IFE-FCE, p. 516. 
El segundo problema presente en la Declaración de 1789, sería el de quién debería tener derecho a la participación política: todos los hombres o sólo algunos. Dicho en otras palabras, se trataba de un derecho natural o de un derecho positivo, producto de la voluntad de la comunidad política. Este problema se planteó por primera vez de una manera muy clara en la revolución puritana. El grupo radical de los Levellers (Niveladores) dentro del ejército de Cromwell formado por pequeños propietarios, granjeros, comerciantes y artesanos formularon un documento, el Acuerdo del Pueblo. Los Niveladores como representantes de comités de soldados discutieron con los jefes del ejército, lo que consideraban una política contemporizadora con el rey y el parlamento. Temían que este último se convirtiera en un órgano de opresión tan temible como el rey. El primer artículo del Acuerdo expresaba: "I. Que el pueblo de Inglaterra, muy desigualmente distribuido en la actualidad por condados, ciudades y villas, debe estar más indiferentemente repartido para la elección de sus diputados en el Parlamento, según el número de habitantes; las condiciones de su número, lugar y modo serán establecidas antes de que termine sus labores el actual Parlamento." 9

Este primer artículo del Acuerdo dio lugar a una discusión entre los Levellers y Ireton, el representante de Cromwell, en octubre de 1647, en Putney. A Ireton le parecía inaceptable que todo habitante pudiera tener un voto igual para elegir a los representantes. Ireton decía que si esta idea se convertía en regla se crearía un derecho natural absoluto y se negaría todo derecho civil. Para él, sólo deberían participar quienes tuvieran intereses 'permanentes y fijos' en el reino. El coronel Rainborough planteó claramente el punto de vista de los Levellers: "realmente creo que el más pobre de los ciudadanos que haya en Inglaterra tiene, como el más grande, una vida que vivir; y por ello, Señor, creo evidente que todo hombre que tiene que vivir bajo un Gobierno debería, en primer lugar, ponerse bajo él por su propio consentimiento, y creo que el hombre más pobre de Inglaterra no está obligado en sentido es-

\footnotetext{
9 “Acuerdo del Pueblo”, en An Introduction..., op. cit., cap. X, p. 1-15.
} 
tricto para con el Gobierno si no tiene voto para ponerse bajo aquél". ${ }^{10}$ Los Levellers no triunfaron en sus demandas y pasarían muchos años para alcanzar el sufragio universal en Inglaterra. Sin embargo, los Niveladores abrieron una discusión que estaría presente en la teoría liberal durante el siglo XVIII y gran parte del XIX.

En la Revolución francesa apareció el problema planteado por los Levellers: ¿el voto del ciudadano es un derecho natural o una función constitucional? En la Constituyente se impuso la idea de considerar el acto de la elección como una función constitucional. En este sentido, la ley podía determinar las condiciones de los electores. "Por una parte, en efecto, conviene observar que si las Constituciones hubieran considerado a los ciudadanos como titulares propios de la soberanía, habrían tenido que llegar al gobierno directo por el pueblo, y no hubieran podido detenerse en esta clase de gobierno indirecto que se ejerce por la acción electoral del pueblo y solamente en la medida de esta acción electoral; el hecho de que los ciudadanos no recibían de la Constitución sino un poder electoral basta para probar que el sufragio sólo es una función constitucional... Para la Constituyente todo miembro de la nación es desde luego ciudadano, pero todo ciudadano no es elector. Tal es el origen de la célebre distinción entre el ciudadano pasivo y el ciudadano activo." 11

El tercer asunto se refiere a los procesos electorales. Derivados de estos principios de representación y derechos políticos, los sistemas electorales, principalmente el francés, desarrollarían una serie de características que pasarían íntegramente al mundo hispano y, por supuesto, a nuestro país. Entre ellas podemos enumerar: 1) el voto considerado como una función constitucional, y por lo tanto, regulado por la Constitución y las leyes. 2) Las restricciones, mayores o menores, para ser elector. 3) Sistema indirecto de elecciones, para el caso francés en dos grados, para España y México en tres instancias. 4) La población como base de la elección. 5) Separación entre elección

${ }^{10}$ Citado en A. J. Carlyle, La libertad politica 1982, México, FCE, p. 249-51.

${ }^{11}$ R. Carré de Malberg, Teoría General del Estado, 2001, México, UNAM-FCE, p. 1122-3. 
y deliberación, y por lo tanto, los electores se limitaban a realizar la elección sin deliberar previamente. 6) La propiedad o el ingreso como garantía para una buena elección. 7) El propietario como modelo de ciudadano. 8) La herencia de prácticas tradicionales como el voto en asamblea y el llamado nominal. 9) La no existencia de candidaturas, campañas electorales, ni candidatos reconocidos o plataformas. 10) La elección como una pedagogía que llevaba a formar buenos ciudadanos. 11) La separación entre electores y elegidos; la única relación se establecía en el acto electoral y una vez elegida una persona, el representante lo era de la nación y rompía todo vínculo u obligación con los representados. 12) La sección electoral considerada sólo como una medida administrativa que no alteraba la unidad esencial de la nación. ${ }^{12} \mathrm{Si}$ es verdad que estos principios constituyeron el esquema general de las elecciones durante la Revolución francesa, entre 1789 y 1799, la elección de 1792 y la Constitución de 1793 fueron un paréntesis muy importante en la forma de conceptuar el voto y los procesos electorales. Bajo la influencia de los jacobinos y las ideas de Rousseau, en este paréntesis el voto fue considerado como un derecho natural y el sufragio se amplió a todos los ciudadanos. Al pasar estas ideas al mundo hispano, vamos a encontrar posiciones a favor de uno u otro sistema de ideas y prácticas electorales.

\section{La Constitución de Cádiz}

El origen del Estado liberal en México se encuentra en las Cortes y la Constitución de Cádiz. Retomando las ideas del liberalismo político, principalmente las de Francia, los diputados a las Cortes se dieron a la tarea de construir un Estado liberal moderno, aprovechando la coyuntura de la invasión francesa y las abdicaciones de Fernando VII y Carlos IV en Bayona, ante las presiones de Napoleón Bonaparte. ${ }^{13}$

${ }^{12}$ Cfr. P. Gueniffey, op. cit.

${ }^{13}$ Miguel Artola, La España de Fernando VII, 1999, Madrid, Espasa, p. 61-7. 
Por primera vez las colonias americanas del Imperio español participarían en la formación del nuevo orden político. A pesar de las distintas posiciones contrarias al dogma liberal, como la de los diputados americanos en favor de una descentralización o la de los diputados peninsulares favorables a la idea de que la Constitución no debería más que ser un paso en la evolución histórica del constitucionalismo español, el documento final expresó las ideas del liberalismo con claridad. Joaquín Varela dice al respecto: "La Constitución para ser tal debía tener un contenido determinado: dar cabida al sistema representativo, dividir los poderes del Estado, y reconocer y garantizar los derechos individuales. Es decir, reconocer el programa sustancial del Estado liberal de Derecho. En segundo lugar, la Constitución debería de ser escrita, sistemáticamente trazada, y recogida en un único documento. En tercer lugar, además de un contenido determinado, debía tener una forma especial: la Constitución debía de ser rígida... En cuarto y último lugar, la Constitución se reducía e identificaba con el texto constitucional... El documento constitucional era la única y verdadera Constitución. Y no suponía la consagración o formalización jurídica de unas relaciones de poder preexistentes, decantadas por la historia, sino que, bien al contrario, se concebía como el origen y fundamento de todos los poderes."14

La Constitución de Cádiz dedicó 76 artículos, del 27 al 103, a las elecciones. La base de la representación sería la población, por cada 70,000 almas se elegiría un diputado, o por una fracción que excediera las 35,000. La elección sería indirecta a través de juntas de parroquia, de partido y de provincia. Las juntas parroquiales elegirían a los electores parroquiales, pero no directamente sino por medio de la elección de 11 compromisarios por cada elector parroquial. Es decir, esta primera elección implicaba dos pasos en vez de uno, lo cual era una diferencia notable con el caso francés. En Cádiz se mantenía la

${ }^{14}$ Joaquín Varela Suanzes-Carpegna, La teoría del Estado en los origenes del constitucionalismo hispánico (Las Cortes de Cádiz), 1983, Madrid, Centro de Estudios Constitucionales, p. 431-2. 
idea de la junta para efectuar la elección al nivel de los ciudadanos, pero la junta era presidida por el jefe político o el alcalde. Los ciudadanos sólo elegían a los escrutadores y al secretario de la junta. Esta junta de ciudadanos elegía a los compromisarios acercándose a la mesa del presidente y nombrando una lista de candidatos que escribía el secretario en su presencia. El ciudadano no podía votarse a sí mismo. Los que obtenían mayor número de votos eran nombrados compromisarios. Estos se retiraban a un lugar separado, sin disolverse la junta, y procedían a la elección de los electores de parroquia. El que obtenía mayoría absoluta de votos era elegido elector parroquial. Para este cargo, se requería ser ciudadano, mayor de 25 años, vecino y residente de la parroquia. El sistema de Cádiz fue muy generoso y casi implicaba el sufragio universal masculino. Sin embargo, no hay que olvidar que la Constitución negaba la ciudadanía en América para las castas y en general por el estado de deudor, de sirviente doméstico, por no tener empleo, oficio o modo de vivir conocido o por hallarse procesado criminalmente. Para el año de 1830 se añadía la condición de saber leer y escribir. ${ }^{15}$

Las juntas electorales de partido estarían formadas por los electores de parroquia, congregados en la cabeza de partido a fin de nombrar a los electores de partido. El número de éstos sería el triple de los diputados que se habrían de elegir. La junta estaría presidida por el jefe político o el alcalde primero del pueblo cabeza de partido. El nombramiento de elector de partido, se haría de uno en uno y por escrutinio secreto, mediante cédulas en las que se escribiría el nombre de la persona que cada uno elegía. Sería nombrado quien tuviera la mayoría absoluta de votos. Si ninguno la alcanzara, los dos que hubieran tenido el mayor número de votos entraban en segundo escrutinio. En caso de empate decidía la suerte. Para ser elector de partido se requerían los mismos

15 “Constitución política de la monarquía española, promulgada en Cádiz el 19 de marzo de 1812" en Enciclopedia Parlamentaria. Leyes y documentos constitutivos de la nación mexicana. De la crisis del modelo borbónico al establecimiento de la República Federal, 1997, México, Cámara de Diputados, Instituto de Investigaciones Legislativas, serie III, vol. I, t. I, p. 98-133. 
requisitos del de parroquia, y la elección podía recaer en una persona de dentro o de fuera de la junta. ${ }^{16}$

Las juntas electorales de provincia se compondrían con los electores de todos los partidos de ella, reunidos en la capital de la provincia. Éstas serían presididas por el jefe político de la capital de la provincia y la junta sólo elegiría a dos escrutadores y al secretario para formar la mesa directiva de la misma. La junta procedía a la votación de los diputados que le correspondían a la provincia. La votación se hacía eligiendo de uno en uno, acercándose a la mesa del presidente, escribiendo el secretario el nombre que cada uno escogía. Quedaba nombrado el que obtuviera la mitad más uno de los votos; si nadie obtenía la mayoría absoluta se procedía a que los dos con mayor votación entraran en segundo escrutinio, quedando elegido el que reuniera más votos. En caso de empate decidiría la suerte. Se procedía después a elegir a los diputados suplentes en razón de uno por cada tres propietarios. Para ser diputado se requería ser ciudadano, con 25 años de edad, nacido en la provincia o avecindado por siete años, pudiendo recaer la elección en un ciudadano de la junta o fuera de ella. El artículo 92 disponía que el diputado tuviera una renta anual proporcionada, procedente de bienes propios. Sin embargo, el artículo 93 suspendía la disposición del 92 hasta que en un futuro las Cortes lo consideraran oportuno. Por el artículo 100, la junta de provincia extendía los poderes del diputado según una fórmula previa. En ella se le otorgaba poderes amplios a todos juntos y a cada uno de por sí, para que como representantes de la nación española pudieran acordar y resolver "cuanto entendieren conducente al bien general de ella en uso de las facultades que la Constitución determina y dentro de los límites que la misma prescribe, sin poder derogar, alterar o variar en manera alguna ninguno de sus artículos bajo ningún pretexto, y que los otorgantes se obligan por sí mismos y a nombre de todos los vecinos de esta provincia, en virtud de las facultades que les son concedidas como electores nombrados para este acto, a tener por válido, y obedecer y cumplir cuanto como

${ }^{16}$ Idem, arts. 59 a 77. 
tales diputados de cortes hicieren y se resolviere por éstas con arreglo a la Constitución política de la monarquía española". ${ }^{17}$

Me he detenido en estas disposiciones porque ellas influyeron de manera decisiva en la primera mitad del siglo XIX en nuestro país. Llama la atención la complejidad del sistema electoral de Cádiz. Los diputados gaditanos partiendo de la experiencia francesa la complicaron más. Francia había tenido dos instancias de elección, Cádiz con la elección de los compromisarios las duplicaba a cuatro. Se mantenía el esquema de la junta electoral pero sin consistencia. En el primer y tercer niveles el voto podía ser oral acercándose a la mesa de la presidencia, pero no se hablaba de voto secreto. En las juntas de partido se habla de votar por cédulas y de voto secreto. En Francia, los ciudadanos elegían a la mesa directiva de las juntas en su totalidad; en Cádiz la autoridad política de cada nivel presidía las juntas y los ciudadanos sólo elegían a los escrutadores y a los secretarios. Para ambos casos, la falta de candidatos y de propuestas políticas, llevaban a la dispersión del voto, y en consecuencia las juntas eran interminables al buscar la mayoría absoluta. El sistema liberal pensaba que debían elegir a los mejores, pero al introducir el sorteo, aunque entraba un factor de mayor democracia, la suerte podía elegir al menos virtuoso o al menos preparado de los contendientes. ${ }^{18}$

Las votaciones en los orígenes del sistema representativo estaban separadas de la deliberación y no se pensaba en los elegidos por su filiación política sino por sus cualidades personales. La realidad fue muy distinta. Ya desde la Revolución francesa y claramente en las elecciones mexicanas bajo la Constitución de Cádiz, la acción de las facciones o de los partidos va a ser un elemento esencial en los procesos electorales. Las facciones van a hacer uso de ellas para acceder al poder. El sistema indirecto era muy propicio para la acción de los partidos. Triunfaba el grupo mejor organizado y más activo en un momento dado. Mariano Otero, quien fue muy crítico de este sistema,

${ }^{17}$ Idem, art. 100.

${ }^{18}$ Cfr. Gueniffey, op. cit. Sobre la elección por sorteo: Bernard Manin, Los principios del gobierno representativo, 1998, Madrid, Alianza. 
señalaba además que bajo esta forma indirecta de elecciones y en el mejor de los casos, si en cada nivel se reunieran los dos tercios de electores y de votos, podía resultar que un diputado sólo representara a 1,581 ciudadanos sobre $120,001 .{ }^{19}$ Apegados a la teoría liberal los diputados gaditanos escindidos en el interior de las Cortes, fueron incapaces de comprender la necesidad de los partidos políticos formales, para el mejor funcionamiento del sistema representativo y de los procesos electorales. En general, el pensamiento liberal europeo y norteamericano del siglo XVIII era muy contrario a los partidos políticos a quienes identificaban con las facciones. El pensamiento sobre los partidos políticos se había originado en Inglaterra y los Estados Unidos. Richard Hofstadter señala tres posiciones fundamentales sobre el tema: 1) los partidos son males que pueden evitarse o suprimirse; esta es la posición de Henry Bolingbroke en Inglaterra y de Alexander Hamilton y los hamiltonianos en los Estados Unidos; 2) aunque los partidos son malos, su existencia es un producto secundario inevitable dentro de un Estado libre; el problema es controlarlos y limitarlos; esta fue la posición de David Hume en Inglaterra y James Madison en Norteamérica; 3) los partidos son necesarios y positivos; es la concepción de Edmund Burke en Inglaterra, que nadie compartía en Estados Unidos. ${ }^{20}$ Paradójicamente, el padre del conservadurismo desarrollaba una teoría de los partidos políticos que sería adoptada por el Estado liberal del siglo XIX. Los diputados gaditanos seguramente no conocían en profundidad el pensamiento inglés o norteamericano sobre este tema. Pero sobre todo, su idea de la representación como depositaria de una soberanía nacional indivisible les llevaba a rechazar cualquier concepto en contra de esa unidad. La realidad se impuso sobre la teoría, y las facciones sustituyeron a los partidos formales, en contextos de violencia hacia el sistema electoral liberal.

${ }^{19}$ Mariano Otero, "Voto particular al Dictamen de la mayoría de la Comisión de Constitución, presentado al Congreso Constituyente en la sesión del 5 de abril de 1847”, en Felipe Tena Ramírez, Leyes Fundamentales de México 1808-1991, 1991, México, Porrúa, $16^{\text {a ed., }}$ p. 460-61.

${ }^{20}$ Richard Hofstadter, La idea de un sistema de partidos. El origen de la oposición legítima en los Estados Unidos, 1780-1840, 1986, México, Gernika, p. 32-48. 


\section{Convocatoria a Cortes de la Junta Provisional Gubernativa}

La Junta Provisional Gubernativa fue formada por Iturbide de acuerdo con los planes de Iguala y Córdoba. Fue instalada en Tacubaya el 22 de septiembre de 1821. Lucas Alamán afirma que la elección de los miembros de la Junta, aunque la hizo Iturbide, no fue arbitraria porque llamó a hombres distinguidos de todos los partidos: "Los individuos designados fueron en número de 38 de los más notables de la ciudad por su nacimiento, fama de instrucción y empleos que ocupaban."21 El principal asunto de la Junta, para lo cual fue establecida, sería el de elaborar la Convocatoria de las Cortes Constituyentes que darían una constitución al Imperio mexicano. La Junta dedicó 19 sesiones al tema, desde el 4 de octubre hasta que salió el decreto de Convocatoria, el 17 de noviembre de $1821 .{ }^{22}$ La comisión de Convocatoria quería convocar con el modelo vigente de Cádiz. Otros proyectos llegaron a la comisión y las elecciones dieron lugar a un debate fuera y dentro de la Junta. Iturbide también presentó un proyecto. Éste contemplaba la formación de dos salas. Una formada por representantes de los estamentos como el clero, la milicia, los ayuntamientos y las audiencias y una segunda sala compuesta de diputados elegidos por el pueblo de forma directa, de acuerdo con la población en una proporción de 50,000 habitantes por un diputado. Iturbide pensaba que de esta forma se eliminaban las elecciones indirectas sucesivas que destruían la relación entre el pueblo y los elegidos. ${ }^{23}$ La propuesta de Iturbide es muy interesante porque nos permite ver que el libertador buscaba un equilibrio. Como Alfredo Ávila afirma, el héroe de Iguala buscaba una

${ }^{21}$ Lucas Alamán, Historia de México desde los primeros movimientos que prepararon su Independencia en el año de 1808 hasta la época presente,1852, México, Imprenta de J. M. de Lara, 5 vols., V, 325-326.

22 Javier Ocampo, Las ideas de un día. El pueblo mexicano ante la consumación de su independencia, 1969, México, El Colegio de México, p. 293.

23 "Indicación dirigida por la Regencia del imperio a S. M. la Soberana Junta Provisional, de 6 de noviembre de 1821", en Vicente Rocafuerte, Bosquejo ligerísimo de la revolución de Mégico, 1984, México, Luz María y Miguel Ángel Porrúa, p. 122-4. 
representación de los diversos intereses del país. ${ }^{24}$ Pero tampoco dejaba a un lado las ideas del liberalismo sobre la representación popular. En este sentido iba más allá de las propuestas de la época y hablaba de una elección directa del pueblo. También se nota en su proyecto la influencia del mundo anglosajón y la búsqueda del equilibrio en una segunda cámara.

La Junta Provisional Gubernativa ni siguió la Constitución de Cádiz ni el proyecto de Iturbide, sino que formó una extraña amalgama muy desafortunada, que posteriormente dio origen a reclamos sobre la legitimidad del Primer Congreso Constituyente. De Cádiz tomó la elección indirecta, pero complicándola aún más. En lugar de cuatro momentos electorales se aumentó a cinco: el pueblo elegía a electores, que elegían ayuntamientos, quienes a su vez elegían a los electores de partido, de provincia y diputados al Congreso constituyente. En el segundo y tercer niveles, los electores se reunían con los ayuntamientos de las cabeceras de partido y con el ayuntamiento de las capitales para hacer la elección. Es decir, una fuerza decisiva en la elección estaba en los ayuntamientos. La base de la elección eran los partidos, no la población. Se entendía por partido las subdelegaciones y se elegirían dos diputados por cada tres partidos hasta el número de 162 con 29 suplentes. Chiapas y Guatemala deberían hacer una elección en la misma proporción, pero se desconocía el número de diputados asignados a ellas. Las provincias que sólo elegían a un diputado podían elegir a cualquier persona que cumpliera los requisitos. Para las provincias con mayor población se les asignaba un número de diputados de diversas clases y el resto podía ser cualquier persona hasta completar el cupo. Así por ejemplo, la provincia más importante de México tenía que elegir 28 diputados propietarios, de los cuales deberían ser un minero, un título, un mayorazgo, un eclesiástico secular, un militar, un magistrado, juez de letras o abogado; Zacatecas, que debía elegir a cuatro diputados, tres debían ser ecle-

${ }^{24}$ Alfredo Ávila, En nombre de la nación. La formación del gobierno representativo en México, 2002, México, CIDE-Taurus, p. 213 y s. 
siástico secular, militar y magistrado o juez de letras o abogado, y el restante, podía ser cualquier persona. En resumen la elección se daba a 114 ciudadanos cualesquiera y 48 por las diferentes clases asignadas a las provincias con mayor población. Los requisitos para votar y ser votado eran mínimos. Para lo primero todos los ciudadanos de todas clases y castas, aún los extranjeros, con 18 años de edad podían votar en el primer nivel de la elección. Los elegidos deberían ser personas adictas a la independencia, con servicios hechos a ella, buena conducta e instrucción. La Convocatoria determinaba la división del Congreso en dos salas con igual número de diputados, pero no señalaba el procedimiento para realizar esta división. ${ }^{25}$

La Convocatoria fue muy cuestionada en su tiempo. Es interesante señalar que el principal reclamo contra ella no se encontraba en el elitismo implicado en la elección por estamentos procedentes de las clases privilegiadas, de la milicia, el clero, la judicatura y las actividades empresariales. El principal defecto de la Convocatoria se veía en la desproporción en la representación, pues Durango tenía 22 diputados y Querétaro, con la misma población sólo uno. Comparando con el Segundo Congreso Constituyente, lo que encontramos es que sólo para el caso de Durango y México, la elección basada en los partidos causaba una gran desproporción con respecto a la elección basada en la población. Para las provincias más pobladas e importantes de Jalisco, Puebla, Michoacán, Oaxaca, Yucatán y Guanajuato encontramos en el Primer Congreso porcentajes de representación muy similares a los del Segundo Congreso Constituyente. ${ }^{26}$

Las elecciones llevaron a un gran número de enemigos de Iturbide al Primer Congreso. Esto no nos debe extrañar: los requisitos eran

25 "Decreto del 17 de noviembre de 1821. Sobre Convocatoria a Cortes", en Manuel Dublán y José María Lozano, Legislación mexicana o colección completa de las disposiciones legislativas expedidas desde la Independencia, 1876, México, Editora Oficial, vol. I, 561-3. Ver el cuadro de Alfredo Ávila en op. cit., p. 219.

${ }^{26}$ Reynaldo Sordo, "El Congreso Nacional: de la autonomía de las provincias al compromiso federal", en Josefina Zoraida Vázquez (coord.), El establecimiento del Federalismo en México (1821-1827), 2003, México, El Colegio de México, p. 116-8. 
mínimos; la relación de diputados ciudadano cualquiera a diputado por clase era de dos a uno; $y$, finalmente, en las clases privilegiadas estaban agazapados un buen número de borbonistas contrarios a Iturbide. El caudillo decía a posteriori: "Se engañó al pueblo diciéndole que existía en él la soberanía; que iba a delegarla en sus diputados y que al efecto iba a nombrarlos, no habiendo tal nombramiento sino por parte de los ayuntamientos, o más bien, de los directores de aquella máquina, que luego quedaron en el congreso después de la cesación de la junta, para continuar sus maniobras como lo hicieron."27

\section{La ley electoral del 17 de junio de 1823}

Los acontecimientos se sucedieron desde el 24 de febrero de 1822 , cuando el congreso abrió sus sesiones con grandes esperanzas. A mediados del siguiente año, después de serios conflictos entre el Congreso y el emperador, el Poder Legislativo se pudo imponer con el apoyo de un movimiento generado en el ejército y desarrollado en las provincias. Iturbide tuvo que abdicar, pero el Congreso quedó desprestigiado y se vio en la necesidad de convocar a un nuevo Constituyente por las presiones de las provincias. El Congreso comenzó a discutir la nueva ley de Convocatoria, el 10 de junio de 1823. La premura del tiempo no dio cabida a un debate amplio sobre el tema. El diputado José Valle, miembro de la comisión de convocatoria, explicó que se había tomado en cuenta todo lo escrito sobre la materia para formar el proyecto de elecciones, pero habían seguido principalmente la Constitución española, e incluso se habían copiado literalmente algunos artículos. ${ }^{28}$ En una semana estaba lista la Ley de Convocatoria. Ésta constaba de 90 artículos. La base de la elección sería la población en proporción de un diputado por 50,000 almas; tenían derecho a votar los ciudadanos

${ }^{27}$ Citado en Alamán, op. cit., v, p. 400.

${ }^{28}$ Congreso. Sesión del 10 de junio de 1823, en Historia Parlamentaria Mexicana. Crónicas I, Mayo-Octubre de 1823, 1983, México, Instituto de Investigaciones Legislativas, p. 19-20. 
en ejercicio de sus derechos con 18 años de edad. Las restricciones eran iguales a las de Cádiz. La elección sería indirecta en tres niveles: juntas primarias, secundarias y de provincia. Las juntas en cada nivel eran presididas por las autoridades políticas; en las juntas primarias se suprimía la elección de compromisarios y los ciudadanos votaban acercándose a la mesa de la presidencia de uno en uno. El votante decía los nombres elegidos oralmente y el secretario los escribía en una lista en su presencia. El ciudadano votaba el número de electores que correspondían a la sección; eran electos los que obtuvieran más votos. Para ser elector primario se necesitaban 25 años o 21 siendo casado. Las juntas secundarias se realizaban en las cabeceras de los partidos. La primera autoridad las presidía. Los electores sólo elegían a los escrutadores y al secretario. La elección se hacía uno por uno por escrutinio secreto y mediante cédulas. Salía elegido quien tuviera la mayoría absoluta. Si no, se procedía a segundo escrutinio, entre las dos personas con mayor votación, y salía elegido quién tuviera mayoría. En caso de empate decidía la suerte. Por cada veinte electores primarios se elegía un secundario. Las juntas de provincia se hacían como en Cádiz; las presidía el gobernador y los electores secundarios nombraban dos escrutadores y un secretario. La elección se hacía de uno en uno, diciendo al secretario en voz baja el nombre de cada persona, y el secretario, en presencia del elector, lo escribía en una lista. Sería elegido el que tuviera mayoría absoluta. Si no, se procedía a segundo escrutinio con los dos de mayor votación y sería nombrado el que alcanzara la mayoría. En caso de empate decidía la suerte. Se podía elegir a una persona de dentro o fuera de la junta, lo cual también se acostumbraba a hacer en el segundo nivel. Para ser diputado se requería ser ciudadano en ejercicio de sus derechos, nacido en la provincia o con una residencia de siete años y tener 25 años de edad. ${ }^{29}$

29 "Ley electoral del 17 de junio de 1823", en Enciclopedia Parlamentaria de México, op. cit., serie III, vol. I, t. I, p. 283-9. 
La ley era muy liberal, casi sin restricciones y fue muy apreciada por los federalistas entre 1823 y 1853, y sirvió de modelo en la primera República Federal; esta ley dio origen al Congreso liberal de 1842, y también formó el Congreso Constituyente de 1846, que dio paso a la Segunda República Federal. Fue sin duda, uno de los instrumentos políticos más duraderos de la primera mitad del siglo XIX. Mariano Otero escribía en 1847: "Por desgracia en esta materia (la electoral) nuestro derecho constitucional se resiente del más lamentable atraso: apenas hemos hecho algunos adelantos al respecto del sistema vicioso adoptado por las cortes españolas, que fue con el que se dio a conocer entre nosotros el régimen representativo; y me atrevo a asegurar que en tanto no corrijamos esa parte de nuestra Constitución, inútiles habrán de ser las mejores reformas sobre las demás; porque a todas ellas faltará la condición indispensable de su realización, el nombramiento de los más dignos ciudadanos para el desempeño de las funciones públicas." 30

\section{Derecho al voto y elecciones en la Primera República Federal}

Con la Constitución de 1824, el proceso electoral se hizo más confuso, porque la Constitución sólo disponía que las elecciones fueran indirectas, en una proporción de un diputado por cada 80,000 habitantes o una fracción que excediera de 40,000. El proceso de votación popular indirecta, para el caso de los diputados federales, se definiría de acuerdo a cada una de las constituciones de los estados y para el Distrito Federal y los territorios, por la ley electoral del 12 de junio de 1830. Los estados siguieron, en términos generales, el esquema de Cádiz, pero hubo variaciones de consideración: por ejemplo, Coahuila y Texas, Chiapas, Jalisco y Guanajuato tenían sólo dos niveles de elección. Zacatecas determinó como la base de la elección los partidos y no la población. Puebla ponía 25 años como requisito para votar. El Estado de México, Michoacán, Nuevo León, Oaxaca, Puebla, San Luis Potosí,

${ }^{30}$ Mariano Otero, "Voto particular...”, en Tena Ramírez, op. cit., p. 459-60. 
Estado de Occidente, Tamaulipas y Zacatecas conservaron la elección en tres niveles. Para el caso de Zacatecas, no todos los electores de partido se reunirían en la capital del estado, sino solamente tres por cada partido, previamente sorteados en las juntas de partido. Tabasco presentaba otra peculiaridad, la elección se realizaba en dos niveles, pero se pasaba de las juntas municipales a la estatal, suprimiendo las intermedias. Las constituciones de Chihuahua, Durango, Querétaro y Veracruz dispusieron que una ley constitucional secundaria regularía los procesos electorales. Yucatán omitió el procedimiento para elegir diputados federales y tampoco habló de una ley al respecto. ${ }^{31}$

En general, la Constitución de 1824 establecía requisitos mínimos para participar en la política nacional. Para ser diputado federal, el ciudadano requería tener 25 años de edad, ser mexicano por nacimiento con dos años de vecindad o ser natural del estado que lo elegía o ser extranjero con ocho años de residencia, un capital de 8,000 pesos o renta anual de 1,000 pesos o haber nacido en la América española con tres años de residencia. ${ }^{32}$ Los senadores al Congreso general serían elegidos por las legislaturas estatales, que nombraban dos por cada estado a mayoría absoluta de votos. Para ser senador, los requisitos también eran mínimos: 30 años de edad y los mismos requisitos para ser diputado federal. ${ }^{33}$

El régimen federalista fue muy abierto a la participación política, siguiendo el esquema del liberalismo gaditano. Los ciudadanos que acudían a votar en las parroquias tenían como únicos requisitos el de la edad y el de estar vigentes sus derechos. Para las funciones de elector primario y secundario, la única condición que se hacía más limitante era la edad que aumentaba a 25 años. En general, las constituciones y las leyes electorales tenían muchas imprecisiones que se prestaban a dudas y conflictos en el proceso. El sistema electoral de la Primera

${ }^{31}$ Se pueden consultar las constituciones de los estados en Enciclopedia Parlamentaria..., op. cit., serie III, vol. I, t. I.

32 "Constitución de 1824, artículos 19-24". Todas las citas de la Constitución proceden de la obra de Tena Ramírez. Para simplificar sólo señalaré los artículos correspondientes.

${ }^{33}$ Constitución de 1824, artículos 28-33. 
República Federal fue confuso, muy cuestionado por los escritores de su tiempo y se prestó a muchas irregularidades. Hubo elecciones escandalosas como las de 1826 y 1828, que fueron abiertamente manipuladas por la facción yorkina. $\mathrm{O}$ eran controladas por el grupo en el poder, como las de 1833 por el partido del progreso y las de 1834 por los hombres de bien. El testimonio de un político moderado del año de 1834, cuando el federalismo estaba en crisis, da una idea de lo que habían sido las elecciones en este período, y cómo se había ejercido el derecho al voto de una forma irracional. Juan Gómez Navarrete afirmaba: "y se restituirán a los Congresos el prestigio que han perdido, porque la facilidad con que se ponen y quitan, y la manera rápida con que progresan los pronunciamientos, no tiene ciertamente otro origen, sino el abuso que se hace de las voces, opinión pública y voluntad general, y ese abuso nace de la facilidad con que el partido que cuenta a su favor con la fuerza, o con la protección del gobierno, o de las logias, saca de diputados a los que quiere, haciendo retirar de las juntas populares a la mayoría de los ciudadanos pacíficos, imparciales y verdaderos amigos del orden, que teniendo certeza de que sus votos no han de ser atendidos, y tal vez ni recibidos, se retraen de emitirlos". ${ }^{34}$

La única ley que metió algo de orden en el proceso electoral, durante la Primera Republica Federal, fue la decretada el 12 de julio de 1830, por la administración de Anastasio Bustamante y Lucas Alamán, para el Distrito Federal y los territorios. Ella respondía a la idea de orden de Alamán y de los llamados hombres de bien y serviría de modelo para las leyes electorales del centralismo. Esta ley ponía atención en el primer nivel de la elección, el que se prestaba a un mayor número de fraudes. La ley disponía la formación de un padrón, la entrega de boletas, la elección de la mesa directiva en su totalidad por los ciudadanos, la ampliación de la mesa directiva de cuatro a cinco miembros. El reconocimiento de la boleta y su confrontación con el padrón así como la presencia del comisionado en la mesa directiva durante todo

${ }^{34}$ Juan Gómez Navarrete, Proyecto de ley para el establecimiento de colegios electorales en la República mexicana, 1834, México, Imprenta del Águila, p. 8. 
el proceso electoral. Nadie podría votar sin una boleta legítima ni fuera de su sección. Una vez realizada la elección por individuo, la boleta era firmada por uno de los secretarios. El nombre del elegido era escrito al reverso de la boleta y era leído en voz alta por el ciudadano o el secretario. También la ley disponía castigos para quienes alteraran el orden, falsificaran las boletas, intentaran votar fuera de su sección o influyeran en la regulación de los votos. ${ }^{35}$ Esta ley había avanzado mucho con respecto al sistema de Cádiz. Los hombres de bien, ya durante la Primera República Central, partiendo de este primer ensayo, lograrían mejorar los procesos electorales significativamente.

\section{Derecho al voto y elecciones en la Primera República Centralista}

En 1835 logra triunfar un movimiento por el centralismo, dentro del Congreso, y después de un proceso constitucional complicado, el Congreso reunido en una sola cámara, el 14 de septiembre de 1835, se declararía constituyente, y comenzaría a dar forma a su proyecto centralista por medio de la Constitución de las Siete Leyes. ${ }^{36}$ El grupo centralista que tomaba el poder en 1835 , tenía un proyecto muy bien definido que implicaba limitar la democracia, como una forma de dar estabilidad al sistema político de representación popular. Pensaban que una de las causas de la desorganización política del país había sido la falta de límites al ejercicio de los derechos políticos de los ciudadanos. Para ellos, en la Primera República Federal, las facciones habían abusado del sistema de representación popular, especialmente en los procesos electorales. Estos habían permitido la entrada de prácticamente cualquiera en el juego político y las consecuencias, según los centralistas, no se

35 "Reglas para las elecciones de diputados y ayuntamientos del Distrito y territorios de la República, del 12 de julio de 1830”, en Eduardo Castellanos, Formas de gobierno y sistemas electorales en México, 1996, México, Centro de Investigación Científica Ing. Jorge L. Tamayo, A. C., p. 138-45.

${ }^{36}$ Cfr. Reynaldo Sordo Cedeño, El Congreso en la Primera República Centralista, 1993, México, El Colegio de México-ITAM. 
habían hecho esperar: los cuerpos legislativos habían sido tomados por jóvenes deseosos de lucrar o fanáticos de las ideas de los philosophes, que habían causado grandes trastornos a la sociedad.

Hay que advertir que estas ideas aún eran compartidas por los liberales más sensatos. José Ramón Pacheco, un liberal moderado escribía en 1834: "Hemos estado mal, porque para el alto y delicadísimo encargo de legislador, no hemos buscado más que la fe política, sin exigir en el eligiendo garantías de orden, ni por la familia ni por la propiedad, ni por la profesión o industria. Con esto se explica el fenómeno que parece inconcebible, de que un elector escoge para administrador de los asuntos de la nación a un individuo a quien no encargaría los propios suyos. De allí ha venido que un estudiante ignorantuelo y con la charlatanería del colegio, viene a una cámara, creyéndose un Canning o un Solón, a trastornarnos la sociedad con proyectos que en vez de dirigir la opinión, la irritan y empeoran las cuestiones." 37

Pero aún más, esta conciencia sobre el desorden en las elecciones era también compartida por los mismos liberales radicales, los seguidores de las ideas de los philosophes. Lorenzo de Zavala, uno de los promotores del desorden electoral en la República Federal comentaba: "La ley que arregla las elecciones era copiada, con muy pocas modificaciones, de la de las cortes de España, dejando siempre un campo vasto a toda clase de ciudadanos para votar y ser elegidos. Semejante base es muy perjudicial en un pueblo en que la clase de ciudadanos proletarios no tiene siquiera la capacidad necesaria para discernir entre las personas que deben nombrarse, ni mucho menos conoce los grandes objetivos a que son destinados los ciudadanos que elige. De aquí resulta que no teniendo ningún interés social, por decirlo así, en que salga este o el otro, se ocupa en buscar otro género de intereses más palpable, más físico, más inmediato. En Mérida de Yucatán distribuían tazas de chocolate y daban almuerzos a los indios; en México repartían pulque

${ }^{37}$ José Ramón Pacheco, Cuestión del día. Nuestros males y sus remedios, 1953, Guadalajara, Instituto Tecnológico de Guadalajara, primera parte, p. 41-2. 
y en otros puntos aguardiente. Los más osados entraban en los grupos y daban las listas de los candidatos de su partido, y, regularmente, estos ganaban las elecciones." ${ }^{38}$ Zavala proponía que no sólo se tomara en cuenta la masa de la población como base de la representación, sino que ésta debería de ser un compuesto de tres elementos: población, propiedad e ideas o cuerpo moral. Para fundar su propuesta, Zavala ponía como ejemplo las reformas introducidas en Inglaterra, en donde los privilegios de los terratenientes y los abusos del pueblo habían sido equilibrados por la propiedad. ${ }^{39}$

El pensamiento y las prácticas electorales en Inglaterra y Francia estuvieron a favor del principio de restricción: los elegidos tenían que ser mejores que los electores. En ambos países se había impuesto la idea de la propiedad como garantía de una buena elección. En los Estados Unidos, en la Convención de Filadelfia también se discutieron estas ideas. Entre los congresistas había una corriente a favor de un requisito de propiedad para la elección. De hecho en algunas de las constituciones de los estados ya se habían incorporado restricciones de propiedad. Sin embargo, aunque las ideas se debatieron, no quedaron plasmadas en la Constitución federal de $1787 .{ }^{40}$ Las circunstancias especiales de las Cortes de Cádiz llevaron a conceder casi un derecho al voto universal, con la excepción de las castas americanas. En este problema hubo largos debates entre los diputados americanos y peninsulares sobre conceder o no la ciudadanía a las castas. La negación de los derechos políticos a ellas, desde mi punto de vista, llevó a los peninsulares a no aumentar las restricciones a los aceptados como ciudadanos. A esta situación corresponde la contradicción antes mencionada de los artículos 92 y 93. Además, los diputados necesitaban legitimarse ante una situación tan anómala por la ausencia del rey y la invasión francesa. ${ }^{41}$

${ }^{38}$ Lorenzo de Zavala, Ensayo Histórico de las Revoluciones en México desde 1808 hasta 1830, 1981, México, SRA-CEHAM, t. primero, p. 278.

${ }^{39}$ Idem, p. 278-9.

${ }^{40}$ Bernard, Manin, op. cit., cap. 3, p. 119-63.

${ }^{41}$ José Barragán, Temas del liberalismo gaditano, 1978, México, UNAM-Instituto de Investigaciones Jurídicas, p. 51-75. Ignacio Carrillo Prieto, La ideología jurídica en la cons- 
La situación del constituyente de 1823-1824 sería similar a la de Cádiz. El Segundo Congreso Constituyente necesitaba tener legitimidad frente al movimiento de autonomía de las provincias, la caída de Iturbide y la anulación del Plan de Iguala y los Tratados de Córdoba. El derecho al voto no fue un tema relevante en las discusiones de este congreso. Las restricciones a los derechos políticos hubieran provocado, posiblemente, mayor inestabilidad. ${ }^{42}$

Resulta interesante destacar que las élites políticas de los diferentes partidos o ideologías, a mediados de los años treinta, coincidían en la necesidad de mejorar los procesos electorales. Los centralistas, por lo tanto, estructuraron su proyecto bajo tres principios: a) restringir la participación política, por medio de la propiedad o su equivalente en un ingreso por un trabajo o profesión; b) elegir por mecanismos selectivos a los funcionarios de alto nivel, $\mathrm{y}, \mathrm{c}$ ) definir con precisión las responsabilidades en los procesos políticos-administrativos. El resultado de estas ideas fue un poco contradictorio: por un lado, el sistema político se hizo más complejo y quienes podían participar en él era un menor número de personas, pero por el otro, se definieron los derechos individuales y los centralistas expidieron las mejores leyes electorales de la primera mitad del siglo XIX.

La restricción en la participación política fue dada desde la base misma de la población. La Primera Ley Constitucional hizo una distinción entre mexicano (nacido en México o naturalizado) y ciudadano mexicano (que además de ser mexicano tuviera un ingreso de 100 pesos al año producto de capital o trabajo personal honesto y útil a la sociedad). Sólo el ciudadano tendría los derechos políticos de votar y ser votado. ${ }^{43} \mathrm{El}$

titución del estado mexicano 1812-1824, 1981, México, UNAM-Instituto de Investigaciones Jurídicas, p. 77-90.

${ }^{42}$ Cfr. Actas Constitucionales Mexicanas (1821-1824), 1980, México, UNAM, 10 vols. Acta Constitutiva de la Federación. Crónicas, 1974, México, Cámara de Diputados. Historia Parlamentaria Mexicana. Crónicas II, Febrero-Marzo y Octubre-Diciembre de 1823, 1982, México, Instituto de Investigaciones Legislativas.

43 “Constitución de 1836. Primera Ley Constitucional, artículos 1-15”, en Tena Ramírez, op. cit. Todas las citas de esta Constitución proceden de la misma fuente. Para simplificar sólo citaré el artículo correspondiente. 
ingreso era concebido como garantía de orden e interés por los asuntos de la sociedad. Para ser diputado se requería un ingreso anual de 1,500 pesos y para senador de 2,000 pesos. La mayor edad exigida en 1836 garantizaba la madurez requerida para funciones tan importantes. Para diputados y senadores la edad se aumentaba de 25 a 30 y de 30 a 35 años respectivamente, con respecto a la Constitución de $1824 .{ }^{44}$

La restricción vino también por la relación población-representatividad. La Constitución de 1824 disponía la elección de un diputado por cada 80,000 habitantes y la de 1836 uno por cada 150,000. La de 1824 establecía dos senadores por cada estado y la de 1836 sólo un total de 24 senadores. Los centralistas pensaban en términos de legislaturas más pequeñas que las tenidas en el régimen federal. También la renovación de las cámaras era diferente. La de 1824 renovaba cada dos años en su totalidad a la Cámara de Diputados y la mitad de la de senadores. La de 1836 cada dos años renovaba la mitad de la Cámara de Diputados y un tercio del Senado. ${ }^{45}$ Los centralistas seguramente no conocían el pensamiento norteamericano, que daba mucha importancia a la renovación frecuente de las personas en los cargos de representación. Ellos, al buscar restricciones en el ejercicio del poder, daban más importancia a la permanencia de los legisladores, apostando a la sensatez y madurez de los elegidos. En resumen, podemos decir que, los centralistas pensaban en cuerpos legislativos más pequeños, con personas de más edad y con una mayor permanencia en sus funciones que los federalistas de 1824 , y por supuesto, con la garantía de la propiedad o el ingreso personal.

La elección de diputados siguió el esquema indirecto de los procesos electorales de la Constitución de Cádiz con sus tres instancias. Para elegir a los senadores, la Cámara de Diputados, el gobierno en junta de ministros y la Suprema Corte de Justicia formaban tres listas de 24 individuos, las cuales se remitían a las juntas departamentales; cada

${ }^{44}$ Constitución de 1824, artículos 19 y 28. Tercera Ley Constitucional, artículos 6 y 12.

${ }^{45}$ Constitución de 1824, artículos. 8, 10, 11 y 25. Tercera Ley Constitucional, artículos. $2,3,8$ у 9 . 
junta escogía a 24 personas de las listas y estas nuevas listas eran remitidas al Poder Conservador; este último calificaba las elecciones y nombraba senadores a quienes hubieran reunido la mayoría de votos de las juntas departamentales. ${ }^{46}$ Este sistema de elecciones sucesivas para elegir a los senadores, no rompía con el esquema del sistema popular representativo, ya que las juntas departamentales hacían la elección sobre listas formadas por los otros poderes. El sistema de representatividad popular no se rompía, porque las juntas departamentales eran elegidas por los ciudadanos.

El grupo centralista trató de mejorar los procesos electorales por medio de varias disposiciones constitucionales y una ley de elecciones para toda la República. En la Primera Ley Constitucional fueron definidos los derechos de los ciudadanos, entre los que se encontraba el de votar para todos los cargos de elección popular y poder ser votado para los mismos, siempre que se tuvieran las cualidades exigidas por la ley. También, de forma complementaria, definieron como obligación particular de los ciudadanos el adscribirse en el padrón de su municipalidad, concurrir a las elecciones populares, siempre que no hubiera un impedimento físico o moral, y desempeñar los cargos concejiles o populares para los que fuesen nombrados. ${ }^{47}$

El Congreso sancionó la ley sobre elecciones populares el 30 de noviembre de 1836. Esta ley fue la que determinó los procesos electorales, tanto en la Primera como en la Segunda República centralistas. La ley se fundaba en la de 1830 para el Distrito Federal y los territorios, más las modificaciones fruto de la experiencia de los años del federalismo y las nuevas exigencias del sistema centralista. ${ }^{48}$ En los motivos del proyecto de ley, los legisladores decían que de una buena o una mala elección dependía la suerte de la nación y que se tenía como objetivo que los partidos no se sobrepusieran por la intriga al voto nacional, porque cuando esto sucedía todo el orden constitu-

${ }^{46}$ Tercera Ley Constitucional, artículo 8.

${ }^{47}$ Primera Ley Constitucional, artículos 8 y 9.

48 "Ley de Elecciones para diputados al congreso general y las juntas departamentales", 30 de noviembre de 1836, en Dublán y Lozano, op. cit., III, p. 216-22. 
cional quedaba trastocado: "Entonces el interés privado se sustituye al público: el mérito no es considerado con relación al servicio de la comunidad, sino al del partido o persona: ya no hay justicia, no hay orden: la virtud severa se persigue con ardor: las mejores instituciones no pueden subsistir: la inmoralidad progresa: la ruina de los hombres de bien y la subversión del Estado, son el fin inevitable a que se llega con más o menos prontitud." 49

La ley dispuso que los ayuntamientos o juntas municipales dividieran los términos de su comprensión en secciones de 1,000 a 2,000 almas. Cuatro semanas antes de la elección se harían padrones de las secciones por comisionados surgidos de entre los vecinos. En los padrones se escribiría el número de la sección, el de la casa o la seña de ella, el nombre y oficio del ciudadano y si sabía leer y escribir. Con anticipación se repartirían boletas a quienes tenían derecho a votar. Cualquier ciudadano podía reclamar si no se le había dado boleta o si no aparecía en el padrón. Al reverso de la boleta, el ciudadano escribía el nombre de la persona elegida y firmaba la boleta. Las juntas electorales ya no las presidían las autoridades, sino que la mesa directiva era elegida en su totalidad entre los vecinos. Se podía concurrir personalmente a votar o enviar a otra persona con la boleta debidamente llenada. El secretario de la junta electoral formaba una lista con numeración consecutiva, anotando quién votaba y por quién lo hacía. Las boletas se cotejaban con el padrón. El comisionado que había hecho el padrón permanecía todo el tiempo junto a la mesa de la presidencia para aclarar las dudas. Los votos enviados debían ir legalmente firmados, sin lo cual no se recibían. Nadie podía votar más de una vez, ni hacerlo sin boleta legítima, ni en otra sección en la que no hubiera sido empadronado. Para ser elector primario, se necesitaban 25 años de edad y la ciudadanía vigente. La junta electoral decidía todos los casos conflictivos o dudosos sin apelación alguna e imponía multas

${ }^{49}$ Proyecto de Ley sobre Elecciones Populares presentado al Congreso General en la Sesión del 17 de octubre de 1836 por la comisión respectiva, 1836, México, Impreso por J. M. F. de Lara. 
de uno a 25 pesos a quienes no asistieran a votar. Las elecciones en el segundo y tercer nivel no modificaron sustancialmente el modelo gaditano, a excepción de la importante disposición de que en la mesa directiva de las juntas, y por lo tanto en las juntas mismas, no participaran las autoridades políticas. ${ }^{50}$

Vemos cuánto se había adelantado con respecto a las elecciones bajo el régimen federal: división en secciones, padrón electoral, entrega de boletas, voto firmado, listas de votantes y votados, autonomía del poder electoral e imposición de multas a los remisos y trasgresores de la ley. Es interesante constatar que en las elecciones del centralismo, tanto con la Constitución de 1836 como con la de 1843, no encontramos grandes impugnaciones y conflictos, sino que parecen transcurrir en un clima de mayor orden. Esto se viene a corroborar por el hecho de que en ellas siempre fueron elegidos un buen número de federalistas que estuvieron presentes en los congresos centralistas, incluso alguna elección la ganaron totalmente, como la de 1845, que ya no llegaron al Congreso por el pronunciamiento militar del general Mariano Paredes y Arrillaga. Si los centralistas hubieran podido manipular las elecciones, de seguro no hubieran salido electos federalistas e incluso federalistas radicales. Por esto Mariano Otero y José María Lafragua decían en 1847 que las elecciones bajo el régimen centralista no habían tenido algún interés, porque había dominado la apatía. Seguramente confundían apatía con orden y respeto a la ley. Y así llegamos a una paradoja más de nuestra historia: los centralistas, al querer restringir la participación política, dieron los mejores instrumentos jurídicos para los procesos electorales y permitieron la participación política de la fuerza contraria. Los federalistas, al querer una amplia participación política, fueron sin embargo, quienes más violentaron los procesos de elección y cuando tomaban el poder, no concedían representación a la otra fuerza política.

50 “Ley de Elecciones para diputados...”, op. cit., p. 216-22. 


\section{Derecho al voto y elecciones en la Segunda República Centralista}

En el otoño de 1841, un levantamiento militar dio fin a la Primera República Centralista. El general Antonio López de Santa Anna fue nombrado presidente provisional con plenos poderes. El caudillo militar convocó a un Congreso en 1842, con la ley de 1823, y el resultado fue que los federalistas ganaron las elecciones. El Congreso de 1842 , por sus tendencias liberales, contrarias a los intereses de los militares, entró en conflicto con el presidente provisional. Santa Anna disolvió el Congreso por interpósita persona y formó una Junta de Notables (Junta Nacional Instituyente) para que redactara unas bases de organización de la República. La Junta Nacional fue elegida por el gobierno y las personas que la formaron no fueron las mismas que redactaron la Constitución de 1836.

Las Bases Orgánicas de la República Mexicana se discutieron entre enero y junio de 1843 y fueron sancionadas por el general Santa Anna el 13 de junio de este mismo año. Las Bases fueron presentadas por sus autores como el justo medio entre las constituciones de 1824 y 1836. En lo que se refiere a la participación política los legisladores aumentaron el sistema restrictivo de la Constitución de 1836. Para votar se necesitaba tener 21 años de edad para los solteros y 18 para los casados, más un ingreso anual de 200 pesos. El elector primario, debía tener 25 años y un ingreso de 200 pesos anuales. El elector secundario 25 años y 500 pesos de ingreso anual. El diputado 30 años y 1,200 pesos de ingreso al año y el senador 35 años y 2,000 pesos de ingresos al año. ${ }^{51}$ La Constitución de 1836 limitaba más a la parte de arriba del proceso electoral y la de 1843 la participación de base en la ciudadanía $\mathrm{y}$ los electores.

La elección de diputados siguió el mismo procedimiento que la Constitución de 1836. La población se mantuvo como la base de

51 "Bases Orgánicas de la República Mexicana”, artículos 28, 42 y 150, en Tena Ramírez, op. cit. Todas las referencias proceden de esta fuente. Para simplificar sólo señalaré los artículos correspondientes. 
la elección, en la proporción de un diputado por cada 70,000 habitantes. También dispuso que la Cámara de Diputados fuera renovada por mitades, cada dos años. La elección de lo senadores combinó los procedimientos de las constituciones anteriores y volvió a introducir la elección por clases. El senado estaría compuesto por 63 individuos. Dos tercios de los senadores los elegían las asambleas departamentales, y esta elección se hacía por las siguientes clases: agricultores, mineros, propietarios, comerciantes, y fabricantes. El tercio restante se elegía por el siguiente procedimiento: la Cámara de Diputados, el Presidente de la República y la Suprema Corte de Justicia sufragaban por un número igual de senadores a elegir, serían elegidos aquellos que hubieran tenido el voto de los tres poderes. La Cámara de Senadores elegiría, dentro de los postulados, a los senadores restantes hasta completar el número requerido. Un tercio del senado sería renovado cada dos años. ${ }^{52}$

Conforme a las Bases Orgánicas sólo hubo dos procesos electorales nacionales, en 1843 y 1845 . El 19 de junio de 1843, el gobierno dio la Ley de Convocatoria a elecciones para formar el congreso nacional. En ésta se dispuso la observancia de la ley del 30 de noviembre de 1836, en cuanto no se opusiera a las mismas Bases. Esta ley, como vimos anteriormente, había probado sus bondades durante la vigencia de la Constitución de 1836. El clima de las elecciones de 1843 fue de tranquilidad. El gobierno quería evitar, sin embargo, que triunfaran los federalistas exaltados, como en $1842 . .^{53}$

En general, las elecciones se llevaron a cabo con orden y libertad, aunque se registraron algunas anomalías en Tulancingo, Guadalajara, Chihuahua, Chiapas, Tamaulipas y Tabasco. José Ramón Malo anotaba en su diario: "Se efectuaron las elecciones primarias en esta capital para el nombramiento de diputados al Congreso y miembros de la Asamblea Departamental, reinando el mayor orden y el haber salido compromisarios de todos los colores políticos manifiesta la

52 “Bases Orgánicas de la República Mexicana”, artículos 26, 27, 30-43.

${ }^{53}$ El siglo XIX, 13 de septiembre de 1843. 
libertad con que se hicieron. ${ }^{" 54} \mathrm{El}$ último domingo de septiembre se realizaron las elecciones departamentales. Había gran expectación en la del departamento de México, por el gran número de diputados que se elegían. La elección fue disputada por el gobierno, los federalistas moderados y los federalistas exaltados. En estas elecciones, los federalistas triunfaron y tuvieron amplia presencia en el Congreso y en la Asamblea Departamental. ${ }^{55}$

La derrota del gobierno se debió a que utilizó las leyes electorales de 1836, que, como habíamos visto, separaba el poder público del proceso electoral. Las elecciones habían sido más ordenadas, pero el gobierno no había podido influir en el resultado de ellas. El general Santa Anna, el 3 de octubre, dejó el gobierno al general Valentín Canalizo. El 5 de octubre, el gobierno publicó un decreto declarando que la responsabilidad de Santa Anna, fijada en las Bases de Tacubaya, y que debería conocer el próximo Congreso, era puramente política y de opinión, y que en consecuencia el Congreso no podía anular acto alguno de su administración. Santa Anna se dio cuenta del triunfo de los federalistas en las elecciones y no quería saber nada del próximo Congreso. En definitiva, este Congreso encabezaría un movimiento en diciembre de 1844 que llevaría a Santa Anna al exilio.

Las elecciones de 1845 se llevaron a cabo cuando el gobierno del general José Joaquín de Herrera estaba en crisis y con una fuerte presión para que restableciera el sistema federal, sobre todo por el grupo de los federalistas puros bajo el liderazgo de Valentín Gómez Farías. Los federalistas moderados apoyaban al régimen de Herrera al igual que los centralistas, quienes querían conservar las Bases Orgánicas con reformas sustanciales. El 8 de julio de 1845, el gobierno dio la Convocatoria para las elecciones que iban a renovar al poder legislativo. La Convocatoria recogía la ley de noviembre de 1836. Por esta razón, en un clima pro-federalista, y sin tener el gobierno el control de

${ }^{54}$ José Ramón Malo, Diario de Sucesos Notables (1832-1853), 1948, México, Patria, 2 vols., I, p. 231.

${ }^{55}$ El siglo XIX, 22 de septiembre de 1843. 
las juntas electorales, los federalistas exaltados tuvieron una victoria significativa en estas elecciones. Malo, que fue siempre un político moderado, consignó en su diario: "Se efectuaron las elecciones en el edificio de la Universidad con todo orden, y resultó ganada por el Partido Federal, que propuso en una lista encarnada a seis candidatos, los cuales no fueron muy dignos de la capital de la República, y se advirtió que excluyeron de ella, hasta los de su opinión que no se han manifestado exaltados: de trece electos, once fueron de la misma junta. El partido moderado presentó los suyos en lista amarilla: eran hombres decentes y tomados de diferentes colores políticos y sin excluir ninguna clase de la sociedad, no había entre ellos ningún elector primario: no obstante estas ventajas, se perdió esta honrosa postulación." ${ }^{56}$

Los centralistas, a pesar de sus restricciones, no pudieron impedir que los federalistas participaran en los procesos electorales y que los ganaran, al contar con instrumentos jurídicos e institucionales que disminuían la posibilidad del fraude. Una reflexión nos viene a la mente: el supuesto carácter oligárquico del centralismo era un mito. Las restricciones no señalaban un abismo entre las élites y los ciudadanos comunes y corrientes. También esto nos corrobora el hecho de que tanto centralistas como federalistas pertenecían a una misma clase privilegiada dentro de la sociedad mexicana. Las diferencias fuertes entre ambos partidos no procedían del origen social, sino de la diversa forma de concebir la política, la representatividad y el derecho al voto.

\section{Una convocatoria singular}

El 14 de diciembre de 1845, el general Mariano Paredes y Arrillaga se pronunció contra el gobierno de Herrera, con el Ejército de reserva, mediante el Plan de San Luis. El general Paredes, en los meses anteriores al pronunciamiento, había tenido contacto epistolar con Salvador

\footnotetext{
${ }^{56}$ José Ramón Malo, op. cit., I, p. 231.
} 
Bermúdez de Castro, ministro de España en México, y con Lucas Alamán, líder de los conservadores. La idea de Bermúdez de Castro y de Alamán era la de establecer una monarquía constitucional, con un rey español de la casa de Borbón, que diera garantías al clero, a los propietarios, a los comerciantes $y$, en general, a la gente de orden. ${ }^{57}$ La idea fue apoyada por el gobierno español e incluso fue sondeada en Francia e Inglaterra. Paredes, sin embargo, se mantuvo siempre cauteloso, nunca habló abiertamente de monarquía y fue adaptando su posición política a las circunstancias del momento. Sin embargo, lo que movió a Paredes a actuar fue el hecho de que en octubre de 1845 , los federalistas exaltados habían tenido un éxito rotundo en las elecciones. El general Paredes odiaba a los radicales y quiso impedir que llegaran a las cámaras en enero de 1846.

El $1^{\circ}$ de enero de ese año, Paredes entró a la ciudad de México. El día siguiente se reunía con los militares y redactaron un Acta General del Ejército, que hacía adiciones al Plan de San Luis. Siguiendo el esquema de las Bases de Tacubaya de 1841, el jefe de la revolución formaba una Junta de representantes de los departamentos, para designar la persona encargada del poder ejecutivo, que obviamente sería el general Paredes. El presidente provisional estaría sujeto a las leyes vigentes y se convocaría a un congreso, para expedir una nueva constitución. ${ }^{58}$

La Convocatoria para realizar las elecciones del tan esperado Congreso extraordinario apareció el 27 de enero. El documento fue obra de los conspiradores monárquicos, Salvador Bermúdez de Castro y Lucas Alamán. Este último estuvo a punto de abandonar la tarea porque no encontraba la manera de arreglar la elección por clases. El ministro español se encerró cuatro días con Alamán y entre ambos

${ }^{57}$ Miguel Soto, La conspiración monárquica en México 1845-1846, 1988, México, deOSA, p. 52.

58 “Acta General del Ejército (2 de enero de 1846)", en Josefina Vázquez (coord.), Planes en la Nación Mexicana, 1987, México, El Colegio de México-Senado de la República, libro cuatro: 1841-1854, p. 296-7. 
dieron forma a la Convocatoria. ${ }^{59}$ Los principios de esta Convocatoria fueron también acordados entre Alamán y Bermúdez de Castro: "1. la elección por clases, 2. el número de diputados, 3. el método directo, siempre que fuese posible, 4. la influencia del Gobierno en las operaciones electorales, 5. garantías de mucha consideración en los electores y en los elegibles". ${ }^{60}$

El resultado final fue un documento único en nuestra historia electoral. Se elegían 160 diputados dentro de nueve clases: propietarios, comerciantes, mineros, industriales, profesiones literarias, magistrados, administradores públicos, eclesiásticos y militares. Se establecía una relación población-clase, así México podía elegir 6 propietarios y Oaxaca 2; Jalisco 2 industriales y Querétaro 1; Guanajuato 3 mineros y Chihuahua 1. Pero además, no todos los estados representaban por todas las clases. Cada clase elegía a los de su clase y en algunos casos la elección era directa. Pero lo más notable es que la exigencia censataria se medía por el monto de las contribuciones a la Hacienda pública en el último año, comprobable mediante los recibos de impuestos. Cada clase tenía una forma especial de elección, ya fuera indirecta en dos grados, o directa, así también como los requisitos de propiedad variaban. En la clase de propietarios, por ejemplo, se incluían a los arrendatarios con montos de renta 10 veces superiores al impuesto exigido al propietario. Para la clase eclesiástica se daba un cupo de 20 diputados. Aquí la ley designaba sin necesidad de elecciones a los 10 obispos de la República y al arzobispo de la ciudad de México, procediéndose a la elección sólo del número restante hasta completar los 20 lugares. Las autoridades de cada estado formarían las listas de los pertenecientes a una clase. Además, las votaciones de las diferentes clases no se hacían en la misma fecha, sino en días consecutivos. ${ }^{61}$

${ }^{59}$ Salvador Bermúdez de Castro al Excmo. Sr. Primer Secretario del Despacho de Estado. México, 29 de enero de 1846, en Jaime Delgado, La Monarquía en México (1845-1847), 1990, México, Porrúa, p. 203.

${ }^{60}$ Idem, p. 203.

${ }^{61}$ Ministerio de Relaciones Exteriores, Gobernación y Policía, Convocatoria a elecciones, del 27 de enero de 1846, AGN. FG., 1846, sin clasificar, vol. 1, exp. 3. 
Por primera vez, México tendría unas elecciones en las que no participaba el ciudadano común y corriente, sino sólo las clases privilegiadas, arbitrariamente definidas. Por ejemplo, la lista por la clase de profesiones literarias y artísticas, de los que podían votar en el Departamento de México, que incluía a la ciudad del mismo nombre, se reducía a unas 150 personas, de las cuales muchas eran eclesiásticos, militares, magistrados o administradores, que volverían a votar en otra clase. Porque tal y como definían a las clases, una persona privilegiada podía pertenecer a cuatro o cinco clases a la vez y votar en todas ellas. ${ }^{62}$ Por esta razón tenía sentido realizar las votaciones en días diferentes, para que una persona votara varias veces. Lo que no se discutió, y no aparece en la documentación del AGN, fue el carácter que asumían los diputados. Y aquí habría una gravísima contradicción: elegidos sólo por su clase, si formaban un congreso constituyente y una constitución, tendrían que asumir una representación de toda la nación, difícil de definir dado el carácter limitativo de su representación.

\section{Derecho al voto y elecciones en la Segunda República Federal}

El gobierno del general Paredes no le dio estabilidad al país. La Convocatoria y la formación del Congreso extraordinario aceleraron la caída del régimen. Los federalistas puros establecieron relaciones con el general Santa Anna, exiliado en Cuba, para intentar tomar el poder. Pero sobre todo, el fracaso del general Paredes para hacer frente a la invasión norteamericana precipitó los acontecimientos. El 4 de agosto de 1846, el régimen pro-monárquico de Mariano Paredes y Arrillaga vivió su drama final. En la ciudadela, el general Mariano Salas y Valentín Gómez Farías hicieron un pronunciamiento con el Plan de la Ciudadela. Este constaba de seis artículos, de los cuales tres se referían a la formación de un congreso constituyente. El 6 de

62 "Lista de los individuos que tienen derecho a votar diputados al Congreso Constituyente, por la clase de profesiones literarias y artísticas", AGN. FG., 1846, sin clasificar, vol. 1, exp. 3. 
agosto, el gobierno decretó la Convocatoria para formar el nuevo Congreso constituyente. Esta se basaba en la ley del 17 de junio de 1823, adecuada a las circunstancias de 1846. Los liberales radicales sentían veneración por esta ley electoral. Las condiciones mínimas permitían a cualquier persona ser diputado y daba igualdad de oportunidades a los puros frente a las otras fuerzas políticas. Esta naturaleza popular de la Convocatoria se complementaba con el hecho de que las autoridades controlaban las juntas electorales. Por consiguiente, la influencia de los puros en las elecciones dependía de contar con gobernadores y autoridades políticas de la misma tendencia política. Gómez Farías comenzó, antes de las elecciones, a remover a los gobernadores para colocar a liberales probados en esos puestos. ${ }^{63}$

Sin embargo, la Convocatoria envolvía serios problemas que se podían revertir a los puros. El Congreso constituyente, concebido según la teoría clásica como un congreso formado por el criterio de la población, tendría una sobre-representación en los estados más poblados y una sub-representación en los que tuvieran pocos habitantes. Según el censo de 1842, el total de diputados sería de 141. Siete estados tendrían en conjunto 97 diputados: México, Jalisco, Puebla, Yucatán, Guanajuato, Oaxaca y Michoacán. Con la excepción de Yucatán, el control del Congreso dependería de los estados centrales del México tradicional, región que era de suponerse podría ser más reacia a los cambios y a las ideas reformistas. Los liberales quedaban atrapados en sus concepciones teóricas sobre la representación y eran incapaces de introducir nuevos conceptos que no fueran el de la población, para el caso de los congresos constituyentes unicamarales.

El 22 de agosto de 1846, el gobierno declaró vigente la Constitución de 1824, mientras se elaborara la nueva constitución. Se restablecieron los estados, sus constituciones, y los gobernadores seguirían en sus funciones, pero podían ser removidos por el poder ejecutivo

63 "Convocatoria expedida por el General en Jefe del ejército Libertador Republicano en ejercicio del Supremo Poder Ejecutivo, en 6 de agosto de 1846", México, Imprenta de la Sociedad Literaria, en AGN. FG., sin clasificar. En este documento se habla de departamentos porque la federación no se restableció sino hasta el 22 de agosto de 1846. 
general, en interés del movimiento político de regeneración nacional. ${ }^{64}$ Las elecciones fueron realizadas en los meses de septiembre, octubre y noviembre de 1846. Las dos facciones del liberalismo trabajaron para triunfar. Los centralistas no aparecieron en la contienda y los monarquistas estaban lo suficientemente desprestigiados como para figurar en ese momento. Todo quedaba entre federalistas de ideas liberales, pero irreconciliables en sus puntos de vista y con un fuerte personalismo cultivado alrededor de sus líderes Valentín Gómez Farías y Manuel Gómez Pedraza. Los puros dominaron en Oaxaca, Sinaloa, Distrito Federal, San Luis Potosí, Aguascalientes y Colima, pero fueron derrotados en México, Michoacán, Durango y Veracruz. En Puebla, Jalisco, Querétaro y Zacatecas hubo equilibrio de fuerzas. Un estado de tradición radical, Yucatán, no pudo realizar elecciones por culpa de un movimiento separatista encabezado por Santiago Méndez en Campeche, el 25 de octubre de 1846, lo cual privaría al Congreso general de 12 diputados, probablemente puros. ${ }^{65}$ El Congreso quedaría prácticamente dividido, pero con un mayor número de moderados. Por primera vez en la historia independiente se formaba un congreso donde sólo dos fuerzas políticas se disputaban el control con números equivalentes. Esta situación provocó la anulación de ambas fuerzas y la inmovilidad legislativa, cuando más se necesitaba unir esfuerzos para enfrentar a un enemigo tan temible como los Estados Unidos. La situación del Congreso contribuyó al desastre final.

En una situación crítica, después de la derrota de Cerro Gordo, el Congreso discutió el Acta de Reformas, que vendría a modificar la Constitución de 1824 en ciertos puntos. Estos cambios serían obra de Mariano Otero y pretendían subsanar los problemas que la experiencia

${ }^{64}$ Decreto del gobierno, 22 de agosto de 1846, Dublán y Lozano, op. cit., V, p. 156. Para ver los efectos del federalismo en la guerra con los Estados Unidos se puede consultar: Josefina Vázquez (coord.), México al tiempo de su guerra con Estados Unidos (1846-1848), 1997, México, FCE-El Colegio de México-Secretaría de Relaciones Exteriores.

${ }^{65}$ M. F. Peraza a Juan N. Almonte, (Mérida, 1 de enero de 1847). Benson Latin American Collection, Archivo de Valentín Gómez Farías, número 2223 y M. F. Peraza a Valentín Gómez Farías (Mérida, 2 de enero de 1847), BLAC, AVGF, número 2229. 
habían señalado a la Constitución de 1824. El Acta de Reformas, en nuestro tema, modificó varias cosas. Se elegiría un diputado por cada 50,000 almas, en lugar de 80,000, aumentando con esta medida el tamaño de la Cámara de Diputados. Los requisitos para ser diputado serían los de tener 25 años y ser ciudadano en ejercicio de sus derechos, más las restricciones señaladas en la Constitución de 1824. Además de los senadores que cada estado elegía, habría un número igual al de los estados, electo a propuesta del Senado, de la Suprema Corte de Justicia y de la Cámara de Diputados, votando por diputaciones. Las personas que reunieran esos sufragios quedarían electos y la Cámara de Diputados votando por personas, nombraría a los que faltasen, dentro de los otros postulados. El Senado se renovaría por tercios cada dos años, alternando en ellos, año por año, la elección de los estados con la de las autoridades. Para ser senador se necesitaban 30 años y las mismas condiciones que para diputado. Pero, como condición muy limitante, la ley disponía que los senadores hubiesen ocupado cargos de alto nivel en los poderes, en la diplomacia, la Hacienda pública o en la milicia. El Acta de Reformas hablaba de arreglar las elecciones por una ley general y sugería la adopción de la elección directa. ${ }^{66}$ Como hemos visto anteriormente, Mariano Otero era muy contrario al sistema indirecto de Cádiz.

El 3 de junio de 1847, el Congreso pasó una ley sobre elecciones de los poderes legislativo y ejecutivo. Las elecciones primarias se verificarían en toda la República, el día 29 de agosto; las secundarias el 12 de septiembre, y el 1 de octubre las de diputados. Esta ley tomaba en cuenta las circunstancias de la guerra, la ocupación de varios estados por los norteamericanos, y fue muy importante porque permitió que se formara el Congreso de 1848, y el gobierno de Querétaro tuviera legitimidad, después de la ocupación de la ciudad de México por el ejército invasor. Esta ley tenía la peculiaridad de que la elección de los senadores por los estados la hicieran los electores primarios en las

66 “Acta de Reformas constitucionales", mayo 18 de 1847, en Dublán y Lozano, op. cit., V, p. 275-9. 
juntas de partido, mientras que el tercio restante fuera elegido por el Congreso. La ley no incorporó la elección directa, pero hizo casi directa la elección de los senadores. ${ }^{67}$

Las elecciones se verificaron entre agosto y octubre de 1847 en los estados no ocupados por el invasor. En este proceso siguió la pugna entre puros y moderados. Los moderados actuaron con rapidez desde el principio, porque sabían que el nuevo congreso tendría que ratificar el Tratado de paz que el partido moderado estaba dispuesto a negociar con los norteamericanos. Los puros no le dieron importancia a esta elección y después se arrepintieron, pues ellos estaban a favor de continuar la guerra. Estas elecciones de 1847 presentaron muchas irregularidades, pero el gobierno moderado las pasó por alto para poder reunir al Congreso y aprobar el Tratado de paz. Los puros perdieron la batalla en las elecciones. Los elegidos fueron en su mayoría del partido moderado, que no escatimó medio alguno para influir en este proceso electoral. El sistema representativo había llegado a un gran desconcierto, disimulado con una supuesta legalidad cuando se imponían las vías de hecho. ${ }^{68}$

Para las elecciones nacionales de 1849 y 1851 no hubo mejorías en la legislación electoral. Siguió vigente la ley de junio de 1847 y no se subsanaron los graves problemas de la legislación de los gobiernos federalistas. El derecho al voto siguió siendo casi universal, la acción de los partidos no decayó y el desorden en los procesos electorales se convirtió en un fenómeno cotidiano. Los liberales rechazaban las restricciones, pero no trabajaban en la búsqueda de una mejor organización electoral y no adoptaban, más que tangencialmente, algunos de los avances del centralismo en favor del orden.

Los políticos mexicanos de la primera mitad del siglo XIX adoptaron con pasión las ideas del liberalismo político. Tanto los federalistas como los centralistas creían en el régimen constitucional representa-

${ }^{67}$ Ley sobre elecciones de los poderes legislativo y ejecutivo de la nación, 3 de junio de 1847, Dublán y Lozano, op. cit., v, p. 281-3.

${ }^{68}$ Cfr. Reynaldo Sordo, "El Congreso y la guerra con Estados Unidos de América, 18461848”, en Josefina Vázquez, México al tiempo..., op. cit., p. 47-103. 
tivo popular. Aún posiciones como la de Iturbide o de los hombres de bien aceptaban las ideas liberales, pero con restricciones. Solamente el monarquismo de los años cuarenta llegó a negar la base popular ciudadana de este sistema. El derecho al voto fue debatido, sobre todo en el tránsito del federalismo al centralismo. Los centralistas llegaron a pensar, a mediados de la década de los años treinta, que era necesario limitar este derecho. En este sentido fueron fieles a la mayoría de los liberales de Europa y los Estados Unidos, quienes pensaban que el derecho al voto no era un derecho natural sino una función constitucional que debía ser regulada por la ley. La propiedad o el ingreso o ciertas cualidades de los ciudadanos serían una garantía de orden.

Los procesos electorales también fueron debatidos y analizados por nuestros hombres del siglo XIX. Sin embargo, llama la atención que este debate no se reflejara en mejoras sustanciales en la legislación y en las instituciones del período. Los federalistas fueron siempre fieles al modelo de Cádiz, a pesar de ser muy defectuoso. Los centralistas dieron las mejores leyes electorales, pero también fueron incapaces de superar el sistema gaditano. Esto quizás se explique porque los congresos estuvieron más preocupados por la forma de gobierno, las relaciones con los otros poderes, la guerra, las situaciones de emergencia o la Hacienda pública. Nuestros hombres de todos los colores políticos se lamentaban de la situación electoral, pero poco hicieron al respecto. También influyó que el sistema liberal, para el caso de México, no aceptara formalmente la existencia de los partidos, cuando de hecho aparecieron en la escena política desde la primera elección. Con todas sus limitaciones, esta época encierra un gran valor: en ella se dieron los primeros intentos en nuestro país por construir un estado de derecho y reconocer las libertades de los mexicanos, que en el siglo XXI siguen siendo nuestra principal preocupación. 